\title{
Polyacetylenes of Solidago altissima L.
}

\author{
Ken-ichi Ichihara, Tadashi Kawai and Manjiro Noda \\ Department of Agricultural Chemistry, Kyoto Prefectural \\ University, Shimogamo, Kyoto, Japan
}

Received September 26, 1977

\begin{abstract}
An unknown polyacetylene was isolated from the subterranean stems of Solidago altissima L. in which the two polyacetylenes, dehydromatricaria ester $(T)$ and methyl 10- $\{(Z)-2$-methyl2-butenoyloxy]-(2Z,8Z)-2,8-decadiene-4,6-diynoate (II) had already been found, and its structure was identified as (4Z)-2,4-decadiene-6,8-diyn-4-olide (dehydromatricaria lactone) (III). The lactone (III), as well as I, strongly inhibited the growth of the seedlings of barnyard millet (Panicum crus-galli $\mathrm{L}$. var. frumentaceum TRIN.).

The seasonal variations in the polyacetylene contents of the subterranean stems were closely investigated, with the results that $\mathbf{I I}$ occurred only in the fall of the year while I and II hardly varied throughout the year. II was a major polyacetylene component and the content was $0.9 \sim 1.0 \mu \mathrm{mol} / \mathrm{g}$ fresh wt.
\end{abstract}

A number of polyacetylenes have been isolated from higher plants and higher fungi in recent years. ${ }^{1)}$ However, little is known about the physiological functions of these compounds. Some polyacetylenes have been isolated as biologically active substances, and their antifungal,${ }^{2 \sim 4)}$ allelopathic, ${ }^{5)}$ nematisida ${ }^{(6)}$ and plant growth inhibitory ${ }^{7 \sim 9}$ properties were revealed. Dehydromatricaria ester (I) was isolated from Solidago altissima L. as a plant growth inhibitory substance ${ }^{7}$ and regarded as one of the factors for the great propagating power of this plant. ${ }^{5}$ ? Recently, a new polyacetylene (II) showing inhibitory effect on plant growth was isolated as the second polyacetylenic compound of $S$. altissima. ${ }^{81}$

In the course of an investigation of the lipids of $S$. altissima, a polyacetylene containing a chromophore of conjugated double and triple bonds has been detected. The present communication deals with the structure determination of this polyacetylene (III) and its plant growth inhibitory effect. In addition, seasonal variations in the amounts of the three polyacetylenes (I, II and III) in the subterranean stems of this plant are also described. The structures of these polyacetylenes are as follows:

\section{(I) $\mathrm{CH}_{3}\left(\mathrm{C} \equiv \mathrm{C}_{3} \mathrm{CH}=\mathrm{CHCOOCH}_{3}\right.$,}

(Z) Dehydromatricaria ester

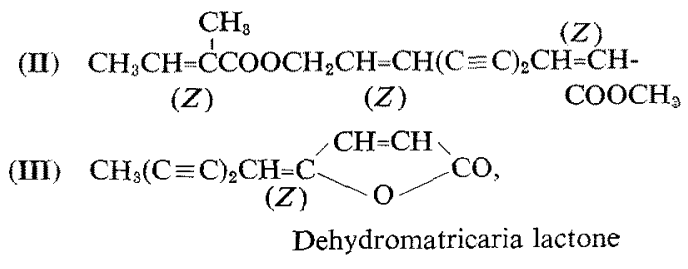

\section{MATERIALS AND METHODS}

UV spectra were determined in benzene, diethyl ether or ethanol with a Hitachi 124 spectrophotometer. IR spectra were measured in chloroform. carbon tetrachloride or potassium bromide with a Shimadzu infrared spectrometer IR $27 \mathrm{C}$. NMR spectra were recorded in deuterochloroform or carbon tetrachloride on a Hitachi R-24 NMR spectrometer $(60 \mathrm{MHz})$.

Isolation and purification of the unknown polyacetylene (III). Lipids were extracted from the subterranean stems of $S$. altissima by the method described previously, ${ }^{83}$ and were chromatographed on a silicic acid column $(50 \times 170 \mathrm{~mm})$ with benzene as eluent. The polyacetylenes (I), (III) and (II) were separately recovered from $200 \sim 1200-\mathrm{ml}, 800 \sim 1600-\mathrm{ml}$ and $1700 \sim$ $2800-\mathrm{ml}$ fractions, respectively. The fractions containing III were concentrated to dryness in vacuo, dissolved in $n$-hexane and rechromatographed on a silicic acid column $(30 \times 120 \mathrm{~mm})$ with the mixtures of $n$ hexane and diethyl ether $(9: 1,8: 2,7: 3,6: 4,5: 5$; $\mathrm{v} / \mathrm{v}$ ), successively. The polyacetylene (III) was eluted with $n$-hexane-diethyl ether (5:5) and separated from I which was eluted with the solvent mixture $(8: 2)$. Subsequently, III was applied on preparative plates of $0.5-\mathrm{mm}$ thickness of silica gel $\mathrm{G}$, and then developed 
with $t$-hexane-diethyl ether $(6: 4, \mathrm{v} / \mathrm{v})(R f$ values: $I$ and II, $0.5 ;$ III, 0.2). A black band under ultraviolet light was scraped off and extracted several times with diethyl ether. The isolated polyacetylene (III) was further purified by thin-layer chromatography on preparative silica gel $G$ plates with benzene-diethyl ether $(8: 2$, $\mathrm{v} / \mathrm{v}$ ) as the developing solvent ( $R f$ values: $\mathrm{I}$ and III, $0.6 ; \Pi, 0.4$ ).

Catalytic hydrogenation of the polyacetylene (III), and reductive deoxygenation and methylation of the hydrogenation product (IV). The ethanol solution of III was stirred over palladium black in a stream of hydrogen at room temperature for $2 \mathrm{hr}$. After removal of the catalyst, the solvent was evaporated in vacuo. The product (IV) $(10 \mathrm{mg})$ was heated under reflux for $24 \mathrm{hr}$ with $4 \mathrm{ml}$ of $48 \%$ hydroiodic acid and $50 \mathrm{mg}$ of red phosphorus. ${ }^{10)}$ The reaction mixture was extracted with $n$-hexane. The extract was washed with sodium bisulfite solution, and then with water. The colorless hexane solution thus obtained was dried over anhydrous sodium sulfate and evaporated in vacuo. The residue was dissolved in $5 \mathrm{ml}$ of metbanol and refluxed for $1 \mathrm{hr}$ with $1 \mathrm{ml}$ of concentrated hydrochloric acid and $0.2 \mathrm{~g}$ of granulated zinc. Diethyl ether was added to the reaction mixture and washed with water. After the organic layer was dried and evaporated, the residue was subjected to gas-liquid chromatography.

Assay for plant growth. The inhibitory effects of the polyacetylenes (I) and (III) on the growth of the seedlings of barnyard millet (Panicum crus-galli $\mathbf{L}$. var. frumentaceum TRIN.) were measured under the same conditions as described previously, ${ }^{8)}$ except that the incubation period was 3 days.

Seasonal variations in polyacetylene contents. The subterranean stems of $S$. altissima were harvested monthly and the lipids were extracted by the method described in the previous paper. ${ }^{8)}$ The three polyacetylenes in the lipids were separated each other by the column-chromatographic procedure similar to that described above. A mixture of $\mathbf{I}$ and $\mathbf{I I I}$ was separated from $I$ by the first silicic acid column chromatography with benzene, and then rechromatographed on a silicic acid column with the solvent system of $n$-hexanediethyl ether. Each polyacetylene thus isolated was determined by UV spectrometry with the $\varepsilon$ values described in the references on $\mathbf{I},{ }^{11)} \mathbf{I I}^{87}$ and $\mathbf{m} .{ }^{12)}$

\section{RESULTS AND DISCUSSION}

The structure of the unknown polyacetylene (III)

As shown in Fig. 1, the IR spectrum of III, which was obtained as yellow crystals by the above chromatographic procedure, exhibited

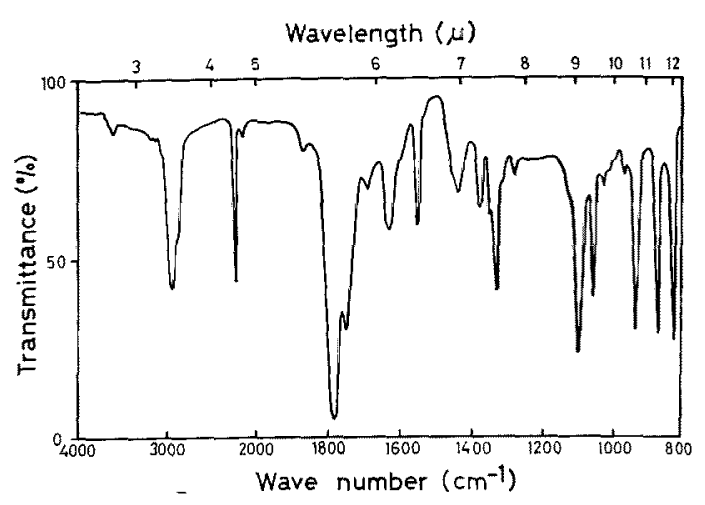

FIG. 1. IR Spectrum of Polyacetylene III (in chloroform).

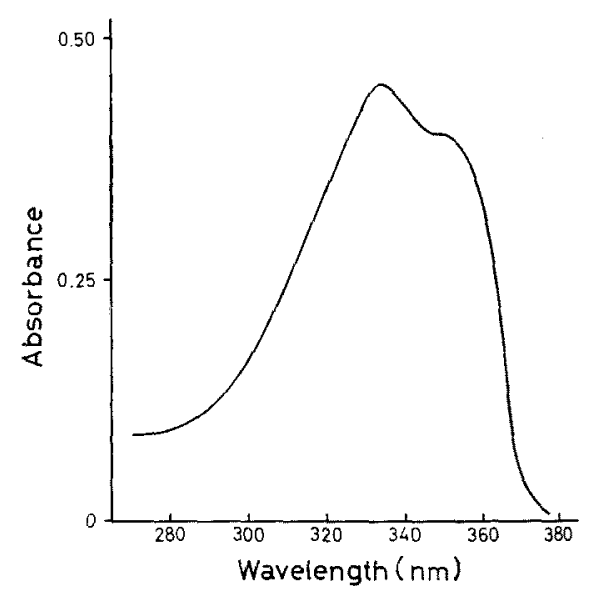

FIG. 2. UV Spectrum of Polyacetylene III (in ethanol).

a sharp absorption band at $2220 \mathrm{~cm}^{-2}$, interpreted as a disubstituted $\mathrm{C} \equiv \mathrm{C}$ stretching frequency. Two very strong absorption bands at 1790 and $1750 \mathrm{~cm}^{-1}$ indicated the presence of an unsaturated-lactone ring. The UV spectrum of III (Fig. 2) was identical with that of dehydromatricaria lactone isolated from Anthemis brachycentros F. Gay. ${ }^{12}$ This indicated the presence of a diyne-diene-one chromophore $\left[(\mathrm{C} \equiv \mathrm{C})_{2}(\mathrm{C}=\mathrm{C})_{2} \mathrm{C}=\mathrm{O}\right]$ in the structure. The catalytic hydrogenation of III required 5.9 moles/mole of hydrogen and the gas-liquid chromatographic retention time of the hydrogenation product (IV) agreed with that of authentic decan-4-olide. The mass spectrum of IV clearly showed that it was a $\gamma$-lactone (Fig. 3). The IR and NMR spectra of IV also 


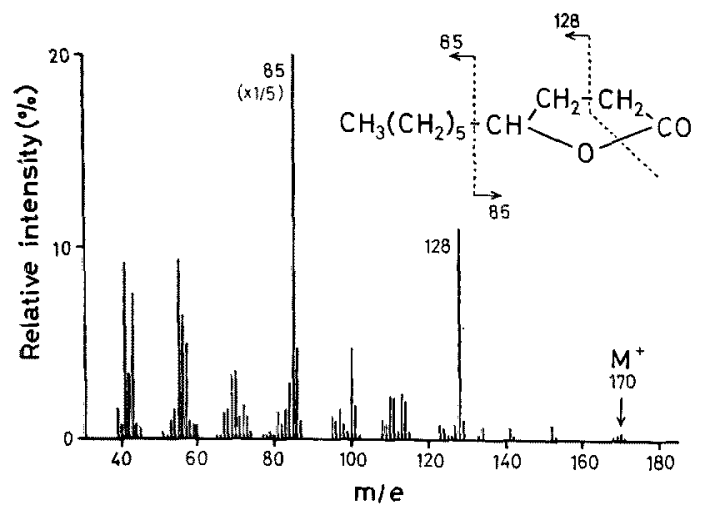

Fig. 3. Mass Spectrum of the Saturated Product (IV) Prepared by Hydrogenation of III.

supported the idea that it was decan-4-olide. As was expected, the hydrolysis of IV with $1 \mathrm{~N}$ potassium hydroxide in ethanol gave a hydroxy-acid (IR: $3200 \mathrm{~cm}^{-1}, \mathrm{OH} ; 1540 \mathrm{~cm}^{-1}$, $\mathrm{COO}$ ). The saturated fatty acid methyl ester prepared by reductive deoxygenation and methylation of IV was identified as methyl decanoate $(\mathbf{V})$ by gas-liquid chromatography.

(III)

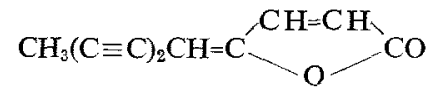

$$
\mid \mathrm{H}_{2} / \mathrm{Pd}
$$

(IV)

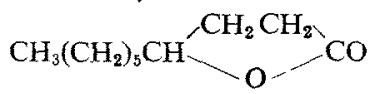

(v) $\mathrm{CH}_{3}\left(\mathrm{CH}_{2}\right)_{8} \mathrm{COOCH}_{3}$

Table I. NMR Spectral Data of Polyacetylene III

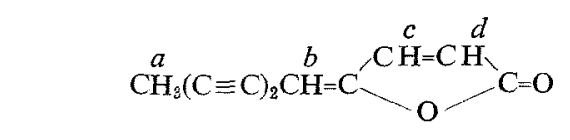

\begin{tabular}{ccc}
\hline $\mathrm{H}$ & $\delta(\mathrm{ppm})$ & $J(\mathrm{~Hz})$ \\
\hline$a$ & $2.00(\mathrm{~s})$ & - \\
$b$ & $5.24(\mathrm{~m})$ & - \\
$c$ & $7.33(\mathrm{~d})$ & 4.7 \\
$d$ & $6.20(\mathrm{~d})$ & 4.7 \\
\hline
\end{tabular}

On the basis of these data, the structure of this polyacetylenic lactone (III) was established as dehydromatricaria lactone, 2,4-decadiene6,8-diyn-4-olide. A sharp absorption band at $940 \mathrm{~cm}^{-1}$ in the IR spectrum of III (Fig. 1) showed that the double bond at $\mathrm{C}-4$ position was $(Z)$-configuration $[(E)$-dehydromatricaria lactone lacks this absorption band. $\left.{ }^{12}\right]$. This structure was well confirmed by the NMR data (Table I) and the results of the elemental analysis (Found: C, 76.07; H, 3.97. Calcd. for $\mathrm{C}_{10} \mathrm{H}_{6} \mathrm{O}_{2}: \mathrm{C}, 75.94 ; \mathrm{H}, 3.82 \%$ ).

Seasonal variations in polyacetylene contents and inhibition of dehydromatricaria lactone (III) on plant growth

Table II shows that dehydromatricaria lactone (III) inhibits the growth of the seedlings of barnyard millet as effectively as dehydromatricaria ester (I) does. However, the season when III appeared in the subterranean stems of $S$. altissima was confined to the fall of the year and it was scarcely detected in the other seasons, while the amounts of I varied with the months in the range of 0.27 to $0.46 \mu \mathrm{mol} / \mathrm{g}$ fresh wt. (Fig. 4). As III can be metabolized into some thioether compounds, ${ }^{13}$ ) the decrease of this polyacetylene in the winter may indicate its conversion into other polyacetylenes. At-

Table II. Inhibition of Polyacetylenes I AND III ON GRowtH OF THE SEEDLINGS of Barnyard Mullet

\begin{tabular}{ccccc}
\hline \multirow{2}{*}{ Polyacetylene } & \multicolumn{4}{c}{ Coleoptile length (mm) } \\
\cline { 2 - 5 } & \multicolumn{4}{c}{ Concentration (ppm) } \\
\hline I & 0 & 1 & 10 & 100 \\
\hline III & 32.7 & 25.3 & 11.0 & 6.0 \\
& 32.7 & 26.7 & 11.4 & 4.0 \\
\hline
\end{tabular}

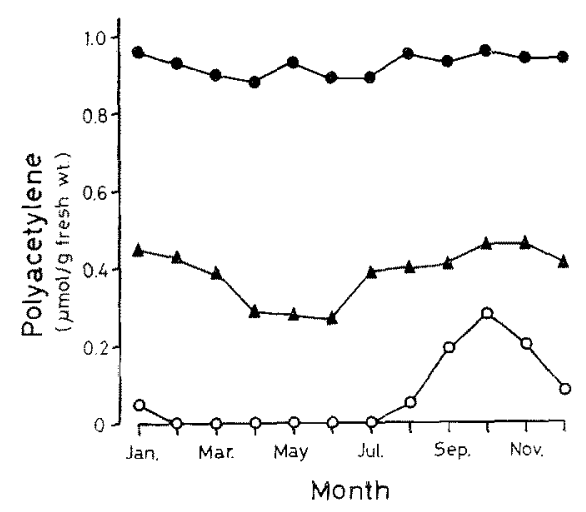

FIG. 4. Seasonal Variations in Polyacetylene Contents of the Subterranean Stems of S. altissima. 
tempts to find these possible metabolites were nevertheless unsuccessful. Therefore, III will be metabolized into a non-polyacetylenic compound or excreted to the soil in the winter. It was worth noting that the variations in the amounts of III did not affect apparently those for I regarded as a precursor of $\mathbf{I I I}{ }^{13}$, The amounts of both $\mathbf{I}$ and $\mathbf{I I I}$ showed maxima in October (Fig. 4). Once $I$ is synthesized as a precursor of II, it seems to be scarcely accumulated in the cells. Kobayashi et al. ${ }^{51}$ have found that $S$. altissima contains $\mathbf{I}$ in February (maximum in wt.) twice as much as in June (minimum in wt.). Their results did not so much differ from the variation curve of I in Fig. 4. The amounts of II hardly varied in the subterranean stems throughout the year.

It was particularly interesting that the major polyacetylene component was not I which was one of the most widespread polyacetylenes, but II. Since $\mathbf{I}$ has been detected in the soil where the plants grow (5 to $6 \mathrm{ppm}$ per dry wt.) $\left.{ }^{5}\right)$ it is probable that $\Pi$ also accumulates there. If so, II may be a more important polyacetylene for allelopathy than the other two. But it is a problem to be solved whether II can actually inhibit the growth of wild plants or not. A difference in growth inhibition of II on rice ${ }^{9)}$ and barnyard millet ${ }^{8)}$ seedlings may show species-specific inhibition of this compound.

The polyacetylenes (II) and (III) may also inhibit seed germination of S. altissima itself as strongly as I did. ${ }^{5)}$ Although this inhibition appears inexpedient for breeding of the plant, it is not necessarily so. When its seed germinates and roots at a place where no polyacetylene is present, it rapidly spreads in all directions with the subterranean stems. Therefore, if these polyacetylenes do not inhibit the growth of the suberranean stems, this plant can propagate without being affected by the polyacetylenes excreted to the soil on which it grows. It may be possible that the growth of

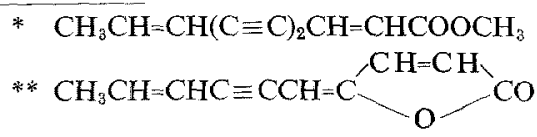

the subterranean stems is not inhibited with the polyacetylenes, because this organ itself contains a relatively large amount of these compounds.

Solidago virgaurea L., which is nearly related to $S$. altissima, also contains several polyacetylenes. ${ }^{14)}$ The major polyacetylenes of the former are matricaria ester* and matri-

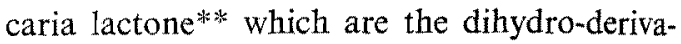
tives of I and III, respectively. In spite of structural resemblances (between $\mathbf{I}$ and matricaria ester and between III and matricaria lactone) and a near relationship between both the plant species, the seasonal variation curves of $\mathbf{I}$ and III in S. altissima differed from those of matricaria ester and matricaria lactone in $S$. virgaurea, ${ }^{14)}$ respectively. Both the species, however, contained the polyacetylenes only in their subterranean parts. It can therefore be presumed that these parts of the genus Solidago are the main sites for polyacetylene synthesis and metabolism.

Acknowledgment. The authors wish to thank Prof. A. Hayashi of Kinki University for mass spectrometric analysis.

\section{REFERENCES}

1) F. Bohlmann, T. Burkhardt and C. Zdero, "Naturally Occurring Acetylenes," Academic Press, Inc., London, 1973.

2) C. A. Thomas and E. H. Allen, Phytopathology, 60, 261 (1970).

3) E. H. Allen and C. A. Thomas, ibid., 61, 1107 (1971).

4) E. H. Allen and C. A. Thomas, Physiol. Plant Pathol., 1, 235 (1971).

5) A. Kobayashi, S. Morimoto and Y. Shibata: Chem. Regul. Plant (Japan), 9, 95 (1974).

6) S. Kogiso, K. Wada and K. Munakata, Agric. Biol. Chem, 40, 2085 (1976).

7) K. Kawazu, A. Nakamura, S. Nishino, K Koshimizu and T. Mitsui, Abstracts of Papers: the Annual Meeting of the Agricultural Chemica Society of Japan, Tokyo, April, 1969, p. 130.

8) K. Ichihara, T. Kawai, M. Kaij and M. Noda Agric. Biol. Chem., 40, 353 (1976).

9) A. Kobayashi, S. Kouya and K. Yamashita ibid., 40, 2257 (1976).

10) C. R. Smith, Jr, and I. A. Wolf, Lipids, 4, (1969). 
11) K. Stavholt and N. A. Sørensen, Acta Chem. 13) F. Bohlmann, T. Burkhardt and C. Zdero, Scand., 4, 1567 (1950).

12) F. Bohlmann, K.-M. Kleine, C. Arndt and S. Köhn, Chem. Ber., 98, 1616 (1965). "Naturally Occurring Acetylenes," Academic Press, Inc., London, 1973, pp. 123 154.

14) J. Lam, Phytochemistry, 10, 647 (1971). 